\title{
Landslides susceptibility assessment using AHP method in Kanyosha watershed (Bujumbura-Burundi): Urbanisation and management impacts
}

\author{
KUBWIMANA Désiré ${ }^{1}$, AIT BRAHIM Lahsen ${ }^{2}$, BOUSTA Mahfoud ${ }^{2}$, DEWITTE Olivier ${ }^{3}$, ABDELOUAFI Abdellah $^{2}$ and \\ BAHAJ Tarik ${ }^{2}$ \\ ${ }^{1}$ University of Burundi, Department of Earth Sciences, Bujumbura, Burundi \\ ${ }^{2}$ Université Mohammed V, Faculté Sciences, Département Sciences de la Terre, Unité de recherche GEORISK. Avenue \\ Ibn Battouta Rabat - Agdal, Boîte Postale 1014, Rabat, Maroc \\ ${ }^{3}$ Musée Royal pour l'Afrique Centrale, Bruxelles, Belgique.
}

\begin{abstract}
The Kanyosha watershed is unstable due to the presence of several landslides, which occupy about $3 \%$ of the study area. They are causing major damage which costs expensive to the Government of Burundi as well as to the population residing there and their properties. Roads, schools, irrigation canals, houses, crop fields, etc., are in danger of collapse. These landslides are mostly naturally occurring but can sometimes be reactivated by heavy rains or human activities during the excavation of building materials from the river bed.In order to carry out this study, we used the multivariate statistical classification with weighting of the responsible parameters of landslides risk to reach the susceptibility map of mass movements in the Kanyosha watershed. Remote sensing, geology, morphometry and bibliography were the data sources for the different parameters. Google Earth images, ortho-photos and field prospecting helped us to identify the landslides needed to validate the susceptibility map.During the fieldwork, we observed 34 landslides of different types, which were superimposed on the mass movements susceptibility map obtained using the Analytic Hierarchy Process (AHP) and compared to previous studies in which the matrix indexing method was used. We found approximately similar results with the consideration of different scales of work. These reasons confirm the validity of the susceptibility map at the level of the Kanyosha watershed, a map which is an essential document for urban planning and land management.
\end{abstract}

Keywords: Landslides, ortho-photos, remote sensing, Kanyosha watershed, susceptibility map, Burundi.

\section{Introduction}

Bujumbura city, which is the political and economic capital of Burundi, is affected by many types of natural hazards, including landslides. The latter is responsible for loss of life among the population, the destruction of roads and houses, distrurbance in electrical power supply and loss of agricultural production [7]. . Unfortunately, areas prone to landsliding are currently being built up due to rapid extension of Bujumbura city.Therefore, to provide information needed to limit this hazard one needs to extend investigations to the region covered by watersheds of the five main rivers accross Bujumbura city, which will be referred to as Bujumbura region hereafter.In this respect, our contribution was limited to the watershed of the Kanyosha River.The aim of this study was to derive a map of susceptibility to landsliding in Kanyosha watershed from auxilliary information using the Analytic Hierarch Process (AHP).

\section{Materials and methods}

To prepare the datat needed to achieve this study, we used three sources of information, namely: (1) Literature on the lithology and pedology; (2) 10-m Digital Elevation Model (DEM) of Burundi from which we derived slope, exposition and drainage maps; (3) Landsat 7+ imagery to derive a map of rock fractures. After creating the maps of the predisposing factors, they were all standardized by classifying them into five classes based on expert knowledge. Then they were assigned weights obtained by pairwise comparison according to the AHP approach. Finally, the weighted factors were summarized using GIS operations to obtain the landslide susceptibility map which was validated using landslides identified from detailed satellite images and field work. Our results were also compared to results obtained by Van Western and Soeters. 


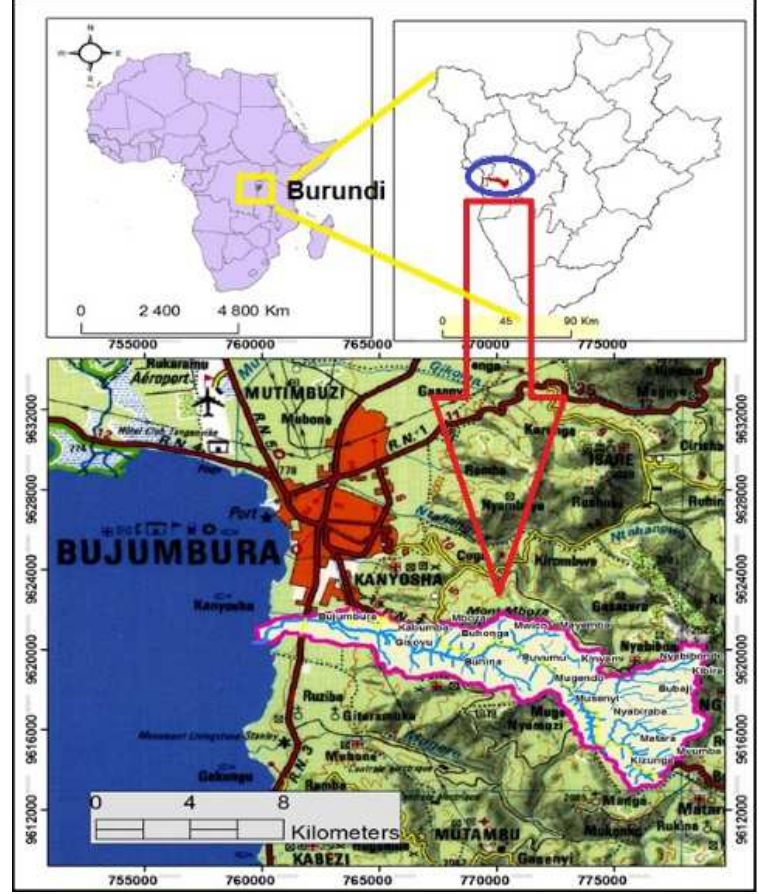

Fig. 1. Study area
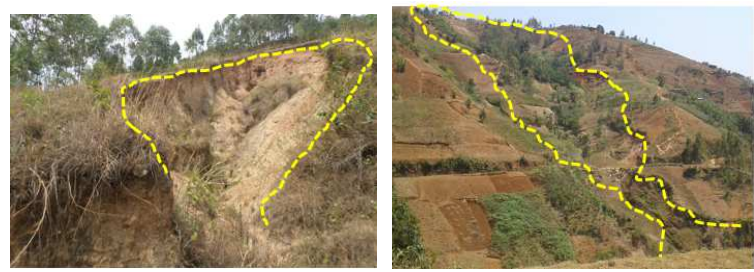

Fig. 2. Examples of observed landslides

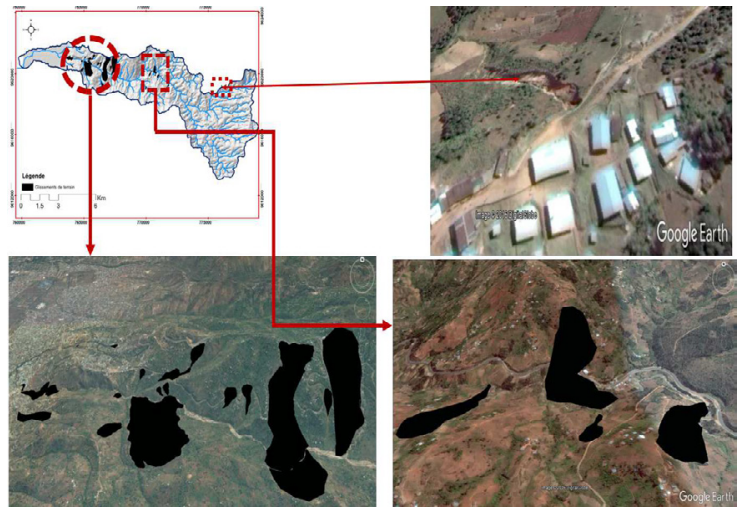

Fig. 3. Landslides identified at Kanyosha watershed

\subsection{Predisposing factors}

\subsubsection{Lithology}

Lithology is one of the main factors controlling the development of deep rotational landslides. [2, 3, 10]. Landslides result from the disruption of the equilibrium between forces acting on a slope, which in turn depend on lithology and the structural pattern of rock types. The stability of slopes is affected by weathering processes and by the fluctuation of the water table. In this study the different facies were classified into five categories according to their susceptibility to landslides (Figure4).

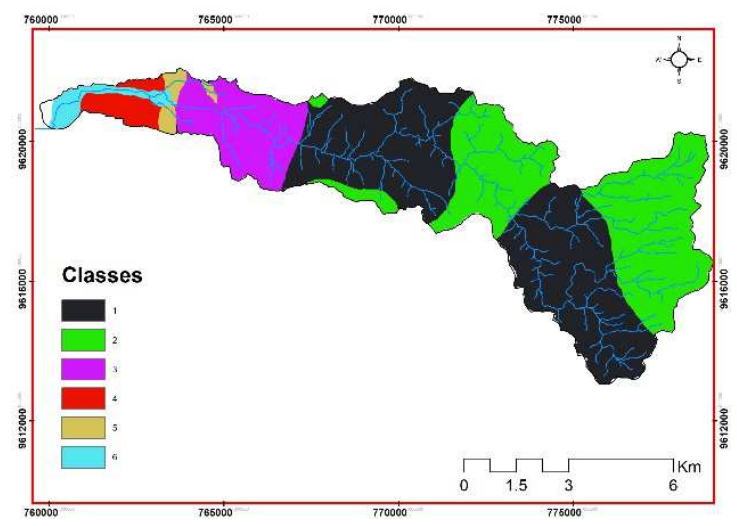

Fig. 4. Lithological map

\subsubsection{Fracturation}

Schistosity, fracturation, stratification or fault planes are weak zones where landslides are often initiated. These features were identified using band 5 of Landsat 7 ETM+. Multi-directional filters were applied to identify linear features that could correspond to fracturation zones. Linear features other than fracturation zones, e.g. roads and river channels were identified and discarded using detailed ortho-photos and Google Earth images.A fiveclass fracture density map was made using GIS operations (Figure5). The susceptibility to landsliding increases as the density of fracturation increases.

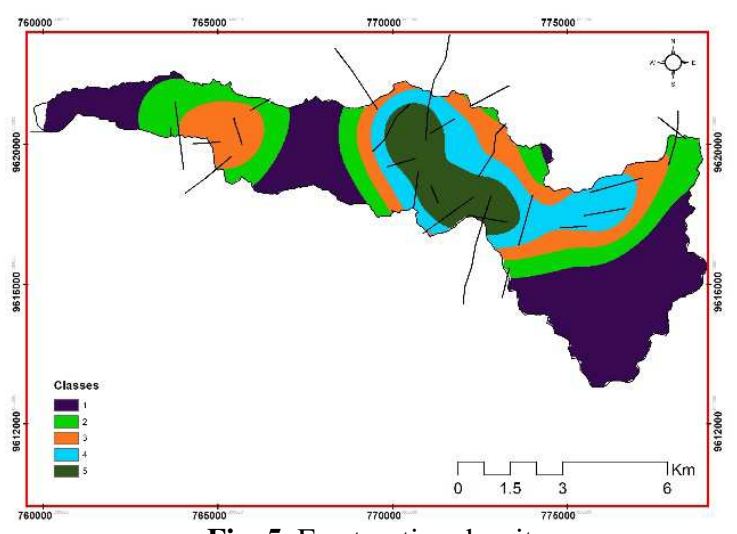

Fig. 5. Fracturation density map

\subsubsection{Pedology}

Soil type is one of the key parameters that influence landsliding. Landslides occur mainly in clayey soils whereas sandy soils resist against landsliding. Deep landslides occur in deep soils and vice-versa.The map on Figure6 was derived from the 1:50 000 soil map of Burundi (Bujumbura sheet). It is composed of five classes of susceptibility to landsliding, from the least to the most susceptible to landsliding. 


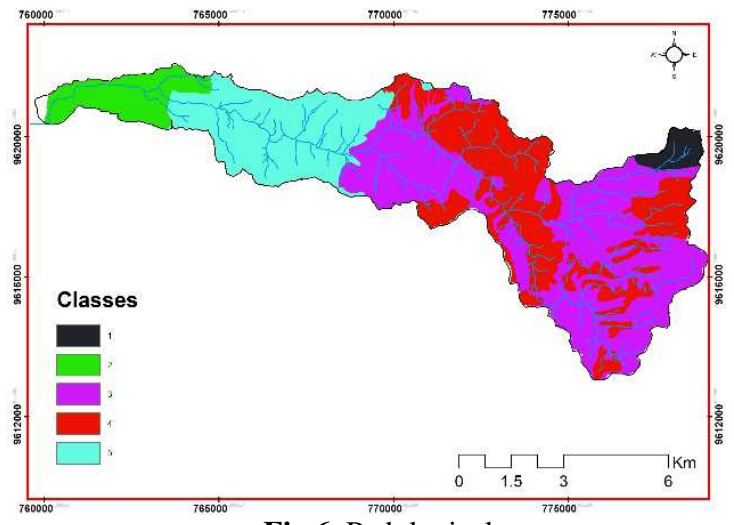

Fig.6. Pedological map

\subsubsection{Drainage}

Water plays a critical role in landsliding by producing hydrostatic pressure within soil and rock voids, fractures and faults and due to percolation forces. It also causes expansion of some clay minerals. In this study the effect of water on landsliding was assessed based on drainage density (Figure7).Areas with high drainage density are also areas under high risk of landsliding.

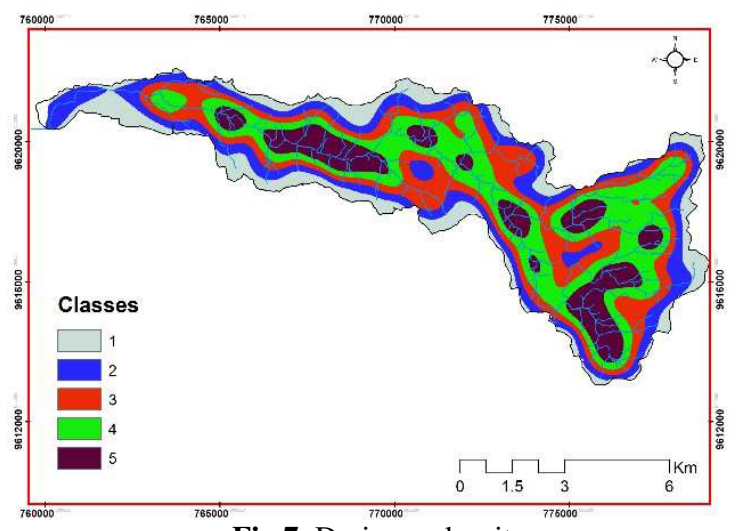

Fig.7. Drainage density map

\subsubsection{Slope}

Slope steepness is certainly the mostly used variable in landslide studies [11].It is directly linked to the shear strength[10].Slope steepness was derived from the 10-m DEM using the "3D analysist"of ArcGIS 10.2.2. The resulting slope steepness map (in degrees) was subsequently classified into a five-class slope map which is shown at Figure8.The susceptibility to landsliding increases as the slope steepness increases.

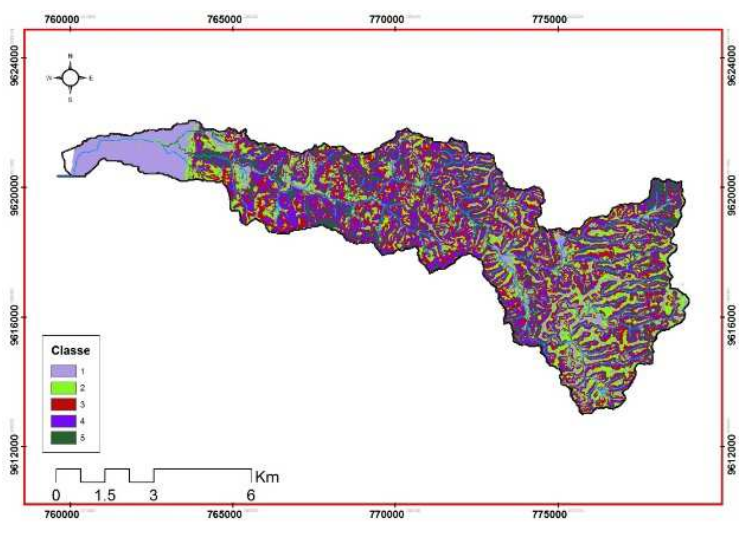

Fig.8. Slope map

\subsubsection{Aspect}

Slope orientation influences the amount of solar radiation and, thus soil humidity Slope orientation also controls the amount of precipitations when these are related to dominant winds with pronounced directional component (9). The slope orientation map was derived from the 10-m DEM using the function « Aspect » of ArcGIS 10.2.2. Slope orientations are defined taking the north as reference and using $0-360^{\circ}$ as clockwise value range. The slope orientation map was classified into an 8class map based on the four cardinal points and on the intermediate directions (Figure9).

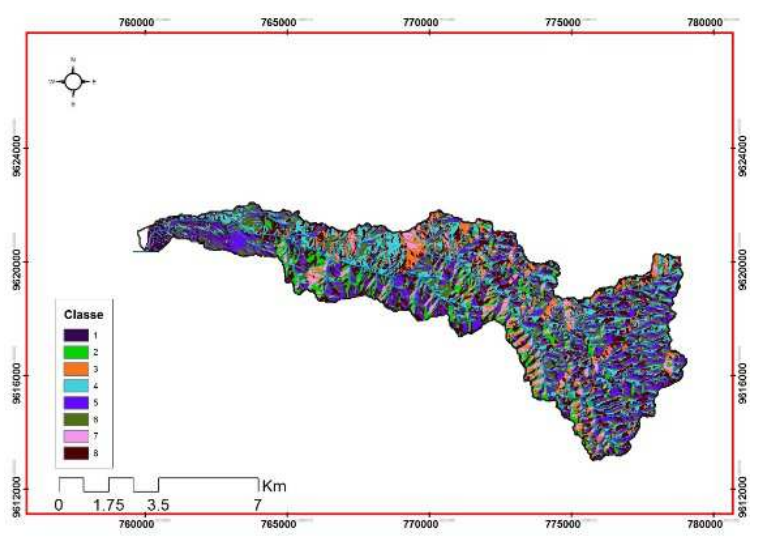

Fig 9. Aspect map

\subsubsection{Elevation}

Elevation is often accounted for in landslides studies as it is linked to precipitations. [5]. Elevation was readily obtained from the 10-m DEM. In our study area, elevation varies from 758 à $2537 \mathrm{~m}$. This elevation map was subsequently classified into a five-class elevation map (Figure10). Low-elevation areas receive small amount of precipitations and, thus have low risk to landsliding.

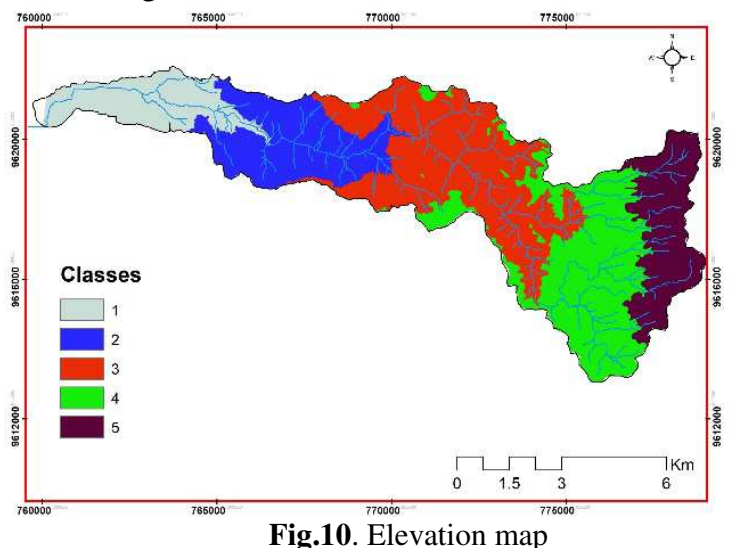

\subsection{Approach principles}

The AHP is a multi-criteria decision support tool that was developed by[12] and that helps to set priorities in order to make the best decision for complex decision making situations involving alternative decisions, decision criteria and trade-offs. After defining the problem you want to solve, four steps are followed to perform this method. : 
1- Determine significant layers.

2- Reclassify the layers.

3- Weight the input layers.

4- Sum up the weighted layers

My concern was always about how I can assign a weight to each layer in a kind of a scientific way. However, Analytic Hierarchy Process (AHP) sorted it out. The main concept of AHP is to pair-wise compare all criteria. A value of 1 expresses "equal importance" and a value of 9 is given for those factors having an "extreme importance" over another factor in a comparison matrix.

\section{Results and validation}

The result of AHP method of the seven factors considered in this study is shown in Table 1.

Table 1. AHP matrix

\begin{tabular}{|c|c|c|c|c|c|c|c|c|}
\hline & Lith & Frac & Pedo & Drai & Slop & Aspe & Elev & W \\
\hline Lith & 1.00 & 2.00 & 3.00 & 4.00 & 5.00 & 6.00 & 7.00 & 0.35 \\
\hline Frac & 0,50 & 1.00 & 2.00 & 3.00 & 4.00 & 5.00 & 6.00 & 0.24 \\
\hline Pedo & 0,33 & 0,50 & 1.00 & 2.00 & 3.00 & 4.00 & 5.00 & 0.16 \\
\hline Drai & 0,25 & 0,33 & 0,50 & 1.00 & 2.00 & 3.00 & 4.00 & 0.11 \\
\hline Slop & 0,20 & 0,25 & 0,33 & 0,50 & 1.00 & 2.00 & 3.00 & 0.07 \\
\hline Aspe & 0,16 & 0,20 & 0,25 & 0,33 & 0,50 & 1.00 & 2.00 & 0.04 \\
\hline Elev & 0,14 & 0,16 & 0,20 & 0,25 & 0,33 & 0,50 & 1.00 & 0.03 \\
\hline
\end{tabular}

The consistency ratio (RC) is 0.0247 , i.e. is smaller than the threshold value of 0.1 , which means that there are small and tolerable inconsistencies [12]. Using map algebra [1] we obtained a landslide susceptibility map for Kanyosha watershed (Figure 11).

The landsliding susceptibility map was validated using field observations (Fig. 4) which are represented by triangles in Fig. 13 and also by comparing our map with the map obtained by [13] and cited by[8].

In total we observed 34 landslides. Their frequences are given in Table 2 and suggest that:

1. Areas with very high susceptibility to landsliding contain $61.8 \%$ of observed landslides ;

2. Areas with high susceptibility to landsliding contain $26.5 \%$ of observed landslides ;

3. Areas with moderate susceptibility to landsliding contain $11.8 \%$ of observed landslides ;

4. No landslide is observed in areas with small to very small susceptibility to landsliding.

Weights in Table. 1 indicate that four out of the seven parameters are more important as they occupy more than 86\%. They are ranked as follows: Lithology (35\%), Fracturation density (24\%), Pedology (11\%), Drainage network density (11\%).

Our results are approximately similar to those obtained by [13] using the "Matrix index" approach and a case study larger than Kanyosha watershed. Together with results from the 34 observed landslides, this similarity supports the validity of our landsliding susceptibility map. Results from field work indicate that about $3 \%$ of Kanyosha watershed correspond to landslides. Areas with very high susceptibility to landsliding correspond to weathered gneissic facies. This is because the weathering product of this facies is composed of clays (silts), which store water in raining season and shrink or collapse in dry season due to the evaporation of the stored water. However, no landslides were observed in fluvio-lacustrine clayey and/or sandy deposits located in the alluvial plain and piedmont. This is explained by small values of slope steepness that characterize these landforms $\left(<17^{\circ}\right)$.

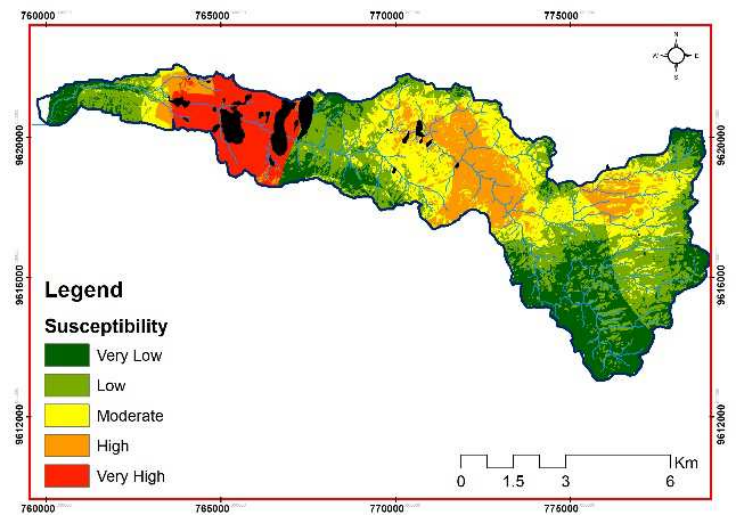

Fig.11. Landslide susceptibility map

\section{Conclusions}

Kanyosha watershed is an unstable zone due to landslides which occupy about $3 \%$ of the area. These landslides are causing important dammages, e.g. roads, schools, irrigation channels, houses, crops, etc.Most of these landslides are of natural origin but can be reactivated human activities, e.g. extraction of building materials in river beds.

In this study we applied the Analytic Hierarch Process (AHP) to derive a landsliding susceptibility map for Kanyosha watershed using remote sensing data, geology, pedology, morphometry and information from literature. The obtained map was validated based on landslides identified from field work, Google Earth images and detailed ortho-photos.

The landsliding susceptibility map is of paramount importance for landuse planning in general and urban planning in particular. Further studies need to be conducted to improve our landsliding susceptibility map, e.g. by applying so-called Weight of evidence method which is more appropriate for any townplanning project. 


\section{References}

1. C.D. Tomlin. Cartographic Modelling In M. Goodchild, D. Maguire, D. Rhind, (Eds.). Geographical Information Systems: Principles and Application. Harlow, Essex, UK: Longman Group, Ltd., 361-370. (1991)

2. C.I. Fernandez, T.F. Del Castillo, R. El Hamdouni, J.C. Montero. Verification of landslide susceptibility mapping: A case study. Earth Surface Processes and Landforms, 24(6): 537-544, (1999)

3. Carrara. Multivariate models for landslide hazard evaluation. Mathematical Geology, 15(3): 403-427 (1983)

4. D. Kubwimana. Contribution à l'évaluation de la susceptibilité aux mouvements de terrains dans le bassin versant de Kanyosha Bujumbura (Burundi) Impacts sur l'Aménagement et l'Urbanisme, (Université Mohammed V, Département des Sciences de la Terre, 2017). Unpublished master dissertation.

5. Gallart, \& N., Clotet. Some aspects of the geomorphic processes triggered by an extreme rainfall event: the November 1982 flood in Eastern Pyrenees. Catena Supplement, 13: 79-85 (1988)

6. I. D. Moore, R.B. Grayson, A.R. Ladson. Digital terrain modeling. A review of hydrological, geomorphological, and biological applications. Hydrological Processes, 5(1): 3-30. (1991)

7. J. Moeyersons, P. Trefois, La protection du site CURGO - Kabezi -Bujumbura contre les risques hydrologiques dans le bassin de la rivière Nyabage. Etude de formulation d'une opération de conservation, (2008)

8. L. Nibigira, S. Draidia, H. Havenith. GIS-based landslide susceptibility mapping in the Great Lakes region of Africa, Case study of Bujumbura Burundi. Engineering Geology for Society and Territory 2, 985 988.

9. M. Mastere, L. Aït Brahim, E.Guelzim, N.El Fahchouch, Landslide assessment by using digital photogrammetric techniques. European journal of remote sensing, (2009)

10. O. Dewitte. Cinématique de glissements de terrain et prédiction de leur réactivation: approche probabiliste dans la région d'Oudenaarde, Université de Liège,( 2006) 11. P.M. Atkinson, \& R. Massari. Generalised linear modelling of susceptibility to landsliding in the central Apennines, Italy. Computers \& Geosciences, 24(4): 373385. (1998)

12. Saaty, The Analytic Hierarchy Process. McGraw-Hill, New York. (1980). 